\title{
SWIM: FUTURISTIC FRAMEWORK FOR STRATEGIC MANAGEMENT PROCESS
}

\author{
Rajendran Muthuveloo and Teoh Ai Ping \\ Graduate School of Business, Universiti Sains Malaysia, Penang, Malaysia
}

Received 2014-06-30; Revised 2014-08-29; Accepted 2014-09-06

\begin{abstract}
The field of strategic management is undergoing significant changes due to the constant changes taking place in the business environment due to issues like emergence of new economic power, conflicts within among countries, environmental crisis and social crisis. This study explicates how inclusiveness of strategic agilities, ethical issues and legal issues into the strategic management process will help organizations to anticipate and manage changes arises to attain business sustainability and meet the organization's vision. It will begin with examining and analyzing the gap existing in the current strategic management process. The paper concludes with a more comprehensive strategic management process that incorporates strategic agilities, ethical issues and legal issues.
\end{abstract}

Keywords: Strategic Management, Corporate Strategy, Organizational Performance, Ethics

\section{INTRODUCTION}

Corporate strategy is vital for organizational business sustainability. A well-defined corporate strategy will assist organization to prepare itself to manage dynamism in the business world (Burgelman and Grove, 2007) due to changes caused by uncertainties such as shift in technology innovation and economic power change to Asia, greater economic of scale in technology, consumer marketing domination, breakthrough technologies, high adoption of innovation, major IT disaster, high economic growth, immigration backlash, corporate social responsibilities, monetary stability, trade blocks/regulation, terrorist attack, natural disasters, global warming, green technology and borderless world.

In order to craft an effective corporate strategy, a good strategic management process that will guide the leaders to incorporate all the essential areas that needed for business sustainability is important. Current strategic management models are based on current capabilities and opportunities available in the market (David, 2011; Pearce and Robinson, 2013). Its Return on Investment (ROI) is based on Above Average Return (AAR) set by the respective industry. The existing strategic management process typically comprises of strategy formulation, strategy implementation and strategy evaluation (David, 2011; Pearce and Robinson, 2013). However, due to the current competitive and dynamic environment, strategies formed based on the existing strategic management process are not comprehensive enough for scholars and practitioners for business sustainability.

The purpose of this study is to show the additional elements need to be incorporated into the strategic management process to provide organizations with better capabilities to manage business sustainability. The additional elements include strategic agilities, legality issues and ethical issues. With the inclusion of these three additional elements, the corporate strategy formed will be more comprehensive and able to provide the expected business sustainability.

The paper begins with explaining the current strategic management process and its gaps. The paper then elaborates the elements that are crucial to address the gaps. Finally, the paper concludes with synergizing the current strategic management process with the gaps to provide the business sustainability.

Corresponding Author: Rajendran Muthuveloo, Graduate School of Business, Universiti Sains Malaysia, Penang, Malaysia 


\section{CURRENT STRATEGIC MANAGEMENT PROCESS}

A typical strategic management process consists of four main section consists of strategic input, strategic formulation, strategic implementation and strategic evaluation. Strategic input covers the internal and external environmental analysis as well as revisiting and understanding vision and mission setting (David, 2011; Pearce and Robinson, 2013). This helps the organization to understand its strength, weakness, threat and opportunity. Upon understanding the strength, weakness, threat and opportunity; strategies are formulated and implemented to utilise the strength to capitalise the opportunity to optimise the return on investment. Strategic evaluation are design to measure the applicability and effectiveness of the strategies formulated and implemented.

The current strategic management process begins with strategic formulation by developing mission statement, performing external audit, performing internal audit to establish long-term objectives. Upon generating, evaluating and selecting strategies based on the long-term objectives, it establishes strategic implementation that includes policies, annual objectives and resources allocation. The final phase in the model involves forming strategy evaluation that includes measuring and evaluating performance. Based on the measurement and performance evaluation, it sends feedback to all previous processes.

Reviewing the strategic management process (David, 2011; Pearce and Robinson, 2013), the long-term goals or vision of the organization is formed based on develop mission, external audit and internal audit. Vision for the organization should be crafted by the founder to ensure the purpose of the existence of the organization. Then, mission should be developed to achieve the vision instead of developing mission first to achieve vision. Once mission is identified, then external audit is carried out to understand the current scenario of the market the organization is located and internal audit to understand the core competencies of the organization.

Based on the traditional model, if vision is formed based on mission, organization might end up in forming a symptomatic corporate strategy instead of root cause corporate strategy. Vision should be the guideline for the organization to operate so that it will clearly inform the leaders of the organization to guide the organization towards achieving the founder's purpose of existence.
Symptomatic corporate strategy normally addresses only the strategies based on symptoms instead of the root cause. For example, when a company's product is not selling well in the market, the marketing company could be blamed for not doing a good job. In the actual fact, the marketing company might be doing well but the product is not meeting the customers' need. In this case, if substantial money, energy and time are spent in improving the marketing company, the organization would not be able to sustain as only the symptoms are addressed. Instead of this, the company should look at how to cater a product that really meets the customers' needs.

\section{IDENTIFYING GAPS IN THE CURRENT STRATEGIC MANAGEMENT PROCESS}

Decades ago business world was dominated by the financial strength of the multinational organization that provides product, services and employment. MNCs monopolise and dictate the business environment and direction. It was taken over recently by the development of technology through new invention and reengineering (Teece, 2010).

As a result of drastic technological development, many nations move away from agricultural to industrial nation. In the process of this progression, substantial damage was done to the environment (Haigh and Griffith, 2009) and human beings. Environmental damages such as global warming, erosions, typhoon and damages to human being like arising of new diseases and health hazards from the use of new kind of raw materials and so on.

Consequence from these damages, legality and ethical issues are becoming prevalent (Jamali, 2008) to the extent where industry would not exist in future if they are involved in offering product or services that is not environmental and human friendly.

The evaluation process of the current strategic management focuses very much of the effectiveness and efficiency of the productivity of the employees and organization. It was not until recently that elements of legality and ethical factors are considered in the strategic management process. The new strategic model introduced in this study called SWIM incorporates legality and ethical consideration in the strategic management process. In addition, this model also provides strategic agility that is needed for corporate strategy to provide business sustainability for the organization. 


\subsection{The SWIM Model}

The SWIM concept arises from the word SWIM itself. The SWIM concept is formed to help managers to SWIM through in the real business world. The SWIM model uses sea as an analogy of business world and the waves are the challenges faced in the business world. In order to attain sustainability, organizations need a proper corporate strategy that has the business sustainability to manage the waves and SWIM through the set target.

The SWIM concept comprises of four main components known as Scenario planning (external and internal environment), identifying winning factor (core competency), implementation (strategic agility) and matching (ethical and legal issues). Figure 1 depicts SWIM concept.

Scenario planning, Winning factor, Implementation strategy and Matching (SWIM) is a futuristic model that will able to take the organization from the red ocean approach to blue ocean approach. This approach is vital for business sustainability as it has the ability to overcome the constraints set by the market and the Return on Investment (ROI) by the previous models. SWIM is able to help leaders formulate effective strategy either at personal level, business level, or corporate level to achieve stakeholders' vision and mission. The formulation of corporate strategy comprises of the strategic input process, strategy formation, strategy implementation, strategic agility and business ethics and legality.

Figure $\mathbf{2}$ below shows the SWIM Strategic Management Process.

The SWIM strategic management process begins with Strategic Input Process that look in-depth into the formation of the organization to understand the purpose of existence of the organisation. This involves key components namely name of organisation, its vision statement, mission statement and tagline.

\subsection{Formation of Organisation}

Every organisation has three main stakeholders being the financier/shareholders, employees and customers. Vision statement normally comes from the founders to inform the financier/management the purpose of the organisation's existence. The leaders of the organisation should understand the vision and make it a shared vision by the members of the organisation so that eventually it would turn out to be the culture of the organisation as organisational culture has strong influence on organisational performance. Generally, every organisation has one vision statement and is not time bound. The only time vision changes when the organisation is taken over or acquired by new shareholders.

Mission statements are for the employees. The leader has to set mission statement to achieve the vision of the organisation. Mission statements are direction for the employees to follow in order to help the leader to achieve the vision of the organisation. Mission statements can be more than one in an organisation and can be time bound.

Tagline is normally created by the organisation to inform the customers on their products/service offerings. The tagline should send clear and continuous message to the customers on the organisation's offerings. Upon understanding the name of organisation, vision statement, mission statements and tagline, the leader should have a good grasp of the organisation's existence.

\subsection{Strategic Input Process}

After understanding the formation of the organisation, the leader could start utilising SWIM strategic management model to formulate corporate strategy. As the first step, the leader should look at the Strategic Input Process to understand the current business situation it contains, which covers scenario planning and winning factor of the organisation at the moment.

\section{S - Scenario Planning (External \& Internal)}

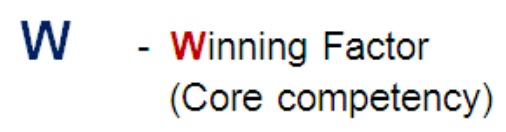
I $\quad$ Implementation
(Strategic Agility)

M - Matching (Legality \& Ethics)

Fig. 1. SWIM concept 


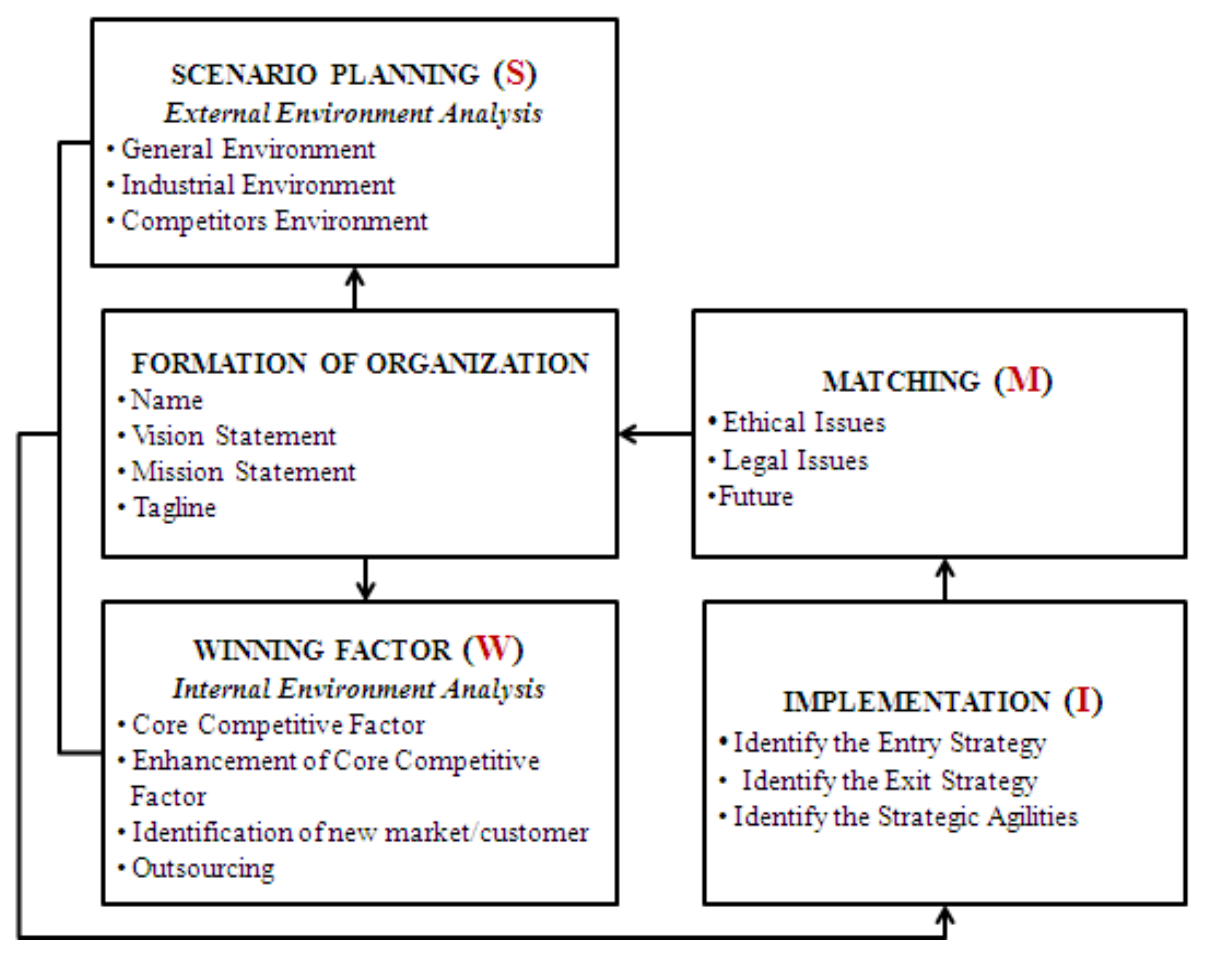

Fig. 2. SWIM strategic management process

\subsubsection{Strategic Planning}

Scenario planning analyses external environment of the organization that covers the three aspects of the environment that consist of general environment, industrial environment and competitive environment.

General environment includes all the macro forces that impact the organizations' business directly or indirectly while the organization/leader has no control over it. For instance, political decision, economy situation, demographic profile, technological influence, physical resources and global changes. In a real business situation, some of these forces are supporting to the business while some could be hindrance to the business. There are also cases where leaders have to completely move out from the current business environment in the case the hindrance factors are too strong to the stage where the organisation could not attain the competitiveness needed to attain the business sustainability.

Industrial environment includes factors that impact the organisation's business directly or indirectly where organisation sometimes has control over the forces. Thus, the challenge for the leader is to utilise the supporting factors to optimize the return on investment while minimizing the impact of the hindrance factors.

Competitive environment includes the factors that impact the organization's business directly and indirectly while the organisation/leader has full control of it. The organisation can opt for the organisation set up/structure, the technology the organisation intends to adopt and the type of employees to hire.

\subsubsection{Winning Factor}

Identifying winning factor will help organisation to understand its source of competitive edge that supports the organization's business growth and sustainability. The four common winning factors considered are customer needs, raw material, product/service and human capital/people. Fulfilling customer needs provide the organisation competitive advantage as it would lead to loyal customers. Unique raw materials provide competitive edge as no other organisation has the opportunity to provide similar service or product. Distinctive products and exceptional services provide total customer satisfaction leads to competitive edge to the organization. Qualifies, dedicated and committed employees could also create competitive 
edge for the organization. Winning factor indicates the competitive advantages the organisation has that will provide the organisation competitive edge over their competitors to capitalise business opportunities to optimize the Return On Investment (ROI).

Upon identifying the winning factor, leaders could relook and enhance further the winning factor to formulate an effective corporate strategy to continue offering same products/service in the same market or in a new market. In addition, leaders could also create a new winning factor using the current factor as basis for offering new products/services in the same market or offering new products/service in a new market.

In essence, the purpose of identifying winning factor is to formulate corporate strategy to optimize the Return On Investment (ROI). In view of this, leaders should also look at the value chain involved in producing the product/service offered in order to optimize every part of the value chain. ROI can only be optimized when every value chain is optimized. In some cases, if the organisation could not optimize a particular value chain through the internal resources and expertise, they could opt for outsourcing.

Outsourcing enables the organization to focus on continuously enhancing the value chain that contributes to the core business while utilizing outsourcing companies to optimize the rest based on their expertise, which will provide a win-win corporation between the organisation and the outsourcing companies. As a caution, companies only outsource the value chain that cannot be optimized because outsourcing always comes with risks.

In conclusion, strategic input process provides the leader a clear indication of the attractiveness of the current market and business environment. Many organisations can end up formulating wrong corporate strategy known as symptomatic strategy without fully understanding the strategic input process. Symptomatic strategy addresses only issues based on symptoms while root cause strategy addresses the actual problem organisation has to address. For business sustainability, organisation needs to address actual problem based on root cause strategy.

Understanding the impact of external environment and the winning factor of the organization, the organisation can move on to implementation and formulating strategies. Firstly, organisations could incorporate innovative and learning concepts to enhance the winning factor of the organisation. Upon enhancing the winning factor of the organisation, the organisation could either continue doing business in the current business environment or location or move on to a new business environment.

In addition, the organization could create a new winning factor by enhancing the existing winning factor and move on to identifying new customers. The new customers can come from the existing location or completely a new location. Upon identifying the potential customers, organisations can formulate implementation moves via entry and exit strategies to convince the targeted customers into doing business with the organisation.

Many organisations focus very much on forming a thorough corporate strategy without understanding the importance of its implementation and agility. Numerous organizations go out of business as they are hero at corporate strategy formation but zero at implementation. A strategy without implementation power leads to failure. As a result of it, due to the dynamic business world, the corporate strategy formed became ineffective quickly.

\section{IMPLEMENTATION}

Upon completing the strategic input process, leaders can move on to next stage in the SWIM model called implementation. Implementation covers three main areas comprise of identification of entry strategies, identification of exit strategies and identification of strategic agility needed for business sustainability.

\subsection{Entry Strategy}

Entry strategy basically means the business tactics used to expand in the current market or moving into new markets. The main entry modes cover Importing or exporting, Co-operations, Strategic alliances, Merger, acquisition and takeover and Greenfield. As strategies are basically utilizing money, energy and time to optimise ROI, each entry strategy has different costs/money, control/energy and risk/time.

Money include the amount of initial investment to start the business, such as bank surety; whereas costs indicate money spent to start the business, such as training people, providing samples, product testing and so on. Costs are the initial amount you need to spend to start and run the business. Thus, to be business savvy, one of our considerations should be minimize the costs when starting the business. This could be achieved through import or export strategy. Importing exporting has the lowest cost and money, cooperation has low cost and 
money, strategic alliances have moderate cost and money. Merger acquisition takeover has high cost and money, while Greenfield has the highest cost and money. If the organisation is tight in cash flow, import and exporting would be the best option of entry mode.

Control indicates how much the organisation has bargaining power and making business decisions. Energy indicates how much difficulties will be incurred in achieving power in the business decisions. In this aspect, Greenfield provides the maximum control and minimum energy for bargaining power and making business decisions. A lot of developing countries encourage Greenfield as this is one of the main form of direct foreign investment. They encourage developed countries towards Greenfield via tax incentives such as pioneer status.

Control and energy in merger, acquisition, takeover is quite complex. The control and energy depends very much on which of the partner has higher bargaining power such as market share, market know-how, technical know-how, financial status, human resources and so on. Strategic alliance has challenges with control and energy if the working relationship between the joint venture or partnership is not clearly specified. The major shareholders have more control in the decision making.

The energy required in the decision making depends very much of the form of strategic alliances. For example, joint venture might be easier than partnership. Cooperation has low control as in most cases, the licensee, franchisee and agencies will be operating independently in their respective countries. Sooner or later, they will learn about the technical know-how of the corporation. Thus, the control will be difficult and in the case of disputes, it will consume a lot of energy to settle it amicably. This is very common in developing countries where they do not have well-defined laws.

Importing and exporting has the lowest control as the representative office, subsidiaries and agents might not focus $100 \%$ on your product. They might be also representing many other similar or different product. Thus, you do not have much control over the representatives, subsidiaries or agents. You need a lot of energy to manage them in the case the working relationship does not go well.

Risk indicates the challenges and the difficulties company will face when adopt particular entry strategy. Time indicates the amount of time required to establish this entry mode. Importing and exporting has the lowest risk and required minimum time to establish. Cooperation has the moderate risk and need moderate time to establish the business relationship. Strategic alliance has moderate risk but need a lot of time to form the relationship. Merger and acquisition has higher risk than cooperation and needs a lot of time to form the business relationship. Greenfield has the highest risk and needs longest time to establish but the potential of return is very high.

\subsection{Exit Strategy}

Exit strategy is normally planned to minimize or avoid loss in investment. Many organisations focus very much on entry strategy and completely overlook exit strategy. As a result, company can go out of business as exit strategy is not included in the corporate strategy, especially when the business environment changed drastically. The three main exit strategies are moving ahead, moving around and moving away.

Among the three strategies, moving ahead means continue being in the business while carrying out downsizing exercise, restructuring or leverage buy out. It has the lowest cost but the highest agility. Moving away refers to moving out from the current business into a completely new business. Moving away involves three types of diversification called value creating diversification, value neutral diversification and value reducing diversification.

Value creating refers to investing capital gain into a new business to grow the business. Value neutral diversification means investing value gain from profitable business into business that are not profitable at the moment but supports current business indirectly and has future potentials for growth. Value reducing diversification means investing capital gain into a business that has no potential at all to save the business from scrutinized by the shareholders. In many cases, this is done by the CEOs or leaders for personal gain. Moving away has moderate cost and moderate agility.

The third strategy called moving around means still being in the same business but increasing their presence or competition through horizontal acquisition, vertical acquisition and related acquisition to strengthen the company's competitive edge. Moving around incurs the highest cost with lowest agility.

Horizontal acquisition means buying companies that have business that is similar to the existing company that can help them to capture the bigger market segment. Vertical acquisition means taking over companies who are currently part of their value chain to have a better control to optimize the ROI. Related acquisition can be 
any acquisition that helps the business growth that does not fall under any of the above mentioned category.

Exit strategy is normally planned to minimize or avoid loss in investment, this can only be achieved if the organisation has carried out a well-defined outright environmental scanning, which provides all the possible changes in the business environment. It is critical to always think through a good exit strategy while forming and defining entry strategies. Most organisations focus a lot of time and money on entry strategy while forgetting the exit strategies. In the past, this could be possible as the business environment was not as dynamic as today. Exit strategies include either being in the existing business, or moving out of the existing business to a new business. In a nutshell, to avoid or minimize losses in investment, a good exit strategy is critical. This exit strategy must be defined while forming entry strategy. It will be too late to design an exit strategy when problem happens.

\subsection{Strategic Agility}

Due to the dynamic business environment, strategic agility is critical to ensure that corporate strategy formulated will be able to handle business environmental changes. Many corporations spend huge amount of money and time to formulate a well-structured corporate strategy but it becomes obsolete and ineffective overnight due to the environmental changes. In fact, this is very common among large organisations.

Strategic agility refers three important elements that comprise of Awareness of early warnings. Decision making speed and Immediate implementation. Strategic agility provides organisations the means to receive or detect the latest happenings related to its business. In other word, we call it the awareness of early warnings that could affect the business. The organisation also must have the capabilities to digest the information received as soon as possible and make quick decision to take the necessary actions in countering the happenings which can impact their business. Making quick decision alone is not sufficient and it means nothing to the organisation unless it is implemented as soon as possible. The organisation should have resource-fluidity where it could mobilise resources to implement it immediately.

Normally two important factors that determine strategic agility are speed of change and nature of change. Entrepreneurial companies normally have the highest speed of change and expose to simplistic nature of change. Companies driven by complicated or detailed strategic planning normally have slowest speed of change and complex or systematic nature of change. Operations driven companies have medium speed of change and medium complexity or nature of change.

This generally means entrepreneurial companies have the highest strategic agilities while companies dealing of complicated or detailed strategic planning have the lowest strategic agility. Thus, companies driven by complicated detailed strategic planning could break down their operations into business units defined according to operations that will help them in improving their strategic agilities.

In order to achieve a good strategic agility, the organisation needs to be of WIN type, as shown in Fig. 3 and has right human capital (Muthuveloo, 2013).

WIN type organisations have the necessary organisational characteristics that are flexible enough to manage environmental changes quickly. The right human capital would provide the ability to utilise technology infinite possibilities and implementation.

In conclusion, strategy implementation covers three important factors, i.e., entry strategies, exit strategies and strategic agility. Entry strategies are designed to optimize ROI. Exit strategies are designed to either optimize ROI or reduce losses. Strategic agility is important to ensure that the corporate strategy formulated has included all the necessary elements to counter any drastic changes in the business environment that could affect the ROI of the business. Strategic agility basically covers early awareness of information, quick decision making and implementation.

\section{W - Worldwide Efficiency \\ I - Implementation Strategy

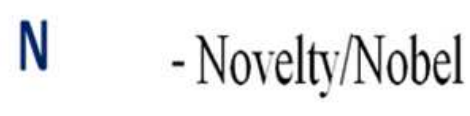

Fig. 3. WIN-futuristic organisation 


\subsection{Matching}

Matching is basically a feedback process where we counter check whether we are fulfilling the vision of the organisation. In addition, matching looks at whether we are fulfilling the vision in an appropriate way which covers business ethics and legality. Matching also reassures that the organisation is fulfilling its purpose of formation and existence. For example, if an organisation is non-profit organisation, its purpose is to work for good causes such as environmental protection, animal shelter and helping underprivileged people. Their purpose of existence is working towards betterment of human life instead of focussing on profit.

On the other hand, if an organisation is formed to optimize Return On Investment (ROI), they need to focus on how to optimise the profit for the shareholders. If this is not checked and balanced continuously while forming corporate strategy, the organisation will lose its base and will not get the necessary support from the stakeholders. The employees of this organisation, too, must have similar kind of vision and needs. In the case which an employee who is interested to optimize ROI while working for non- profit organisation, the organisation will not progress while the employee will be frustrated.

Matching also helps us towards guiding an organisation to be a better place to work. If as a leader, you could understand the purpose of formation and existence of the organisation, you should be able to form a corporate strategy that works towards the goals of the organisation by creating a vision that is shared by all the employees. This eventually will become the culture of the organisation. If the culture of the organisation does not match the purpose of formation or existence, the organisation's corporate strategy will fail. Eventually, the leader of the organisation will have to bear the consequences of this failure such as loosing job, damaging your reputation, or in some cases even lawsuits.

Matching is crucial in order for the management to receive continuous support from the stakeholders in term of business growth and so on. If the formulated strategy and the implementation strategy does not match, the organisation will crack and hence affect its sustainability.

\subsubsection{Business Ethics}

Business ethics are vital for sustainability as the repercussion of being unethical is severe. In the past, if an organisation is found to be involved in unethical business, the organisation bears the responsibilities (may be the CEO of the organisation). However, at present, whoever involved directly in unethical business is responsible for that. If you are the project manager in your organisation and your project fails due to unethical reason, you are responsible directly and your hard-earned image and recognition will be damaged forever. The root cause of unethical boils down to degradation of human values that leads to negative forces within us such as lust, anger, greed, fear, jealously and hatred.

As the result of these negative forces, major conflicts (such as civil wars, terrorism, religious conflict and personal conflict), major environmental crisis (such as global warming, water pollution, air pollution, scarcity of food supply, unmanageable waster, earthquakes, tornadoes, landslides, tsunami) and major social crisis (such as rampant corruption, number of HIV victims, rising of divorce rate, single parents, child abuse, commit suicide, teenage pregnancy) arises.

The common modes of unethical practice are through abuse, discrimination, ignorance and incompetence. Abuse involves cheating, dumping, child employees, sexual harassment by the stronger force on the weaker force (such as developed countries on developing countries). Discrimination differentiates human being based on racial difference, ethics, age, gender, gay and lesbian. Unethical business also take place due to ignorance where the person being abused not aware of it. For example, women are used in advertisement by automobiles companies to promote their products; children are used to promote health products such as vitamins. Unethical business may happen due to incompetency of a person assigned to do a duty. For example, a not welltrained doctor can make mistakes during operation which can cause long-term damage to a patient.

Being unethical is our Careful, Honesty, Openness, Integrity, Confidentiality, Empathy (CHOICE) as discussed below.

Careful indicates whatever you do, you must be careful to avoid carelessness errors or negligence. A little carelessness or negligence can be damaging to your business or organisations. For example, as a front desk worker in a hospital made a mistake in one of the patient's card and the consequence treatment will follow based on the card. In many cases, patients are operated or treated for wrong diagnosis.

Honesty is very important because many people do not realise that cheating someone else is actually cheating yourself. In the end, we could fabricate, falsify, misrepresent data or devise others with our intelligence. You could be lucky if you managed to achieve your wants through this once or twice. But eventually, 
somehow you will be caught. Once you are caught, all your hard-earned reputation will be damaged and in certain cases you might face legal actions.

Openness is critical in business world especially among the business partners in order to create winwin business deals. Employees need to understand clearly the expectation and performance measures to help the organisation in optimizing their performance. Employees should also be allowed to speak out freely in order for them to provide constructive criticism on new ideas that could help the organisation to move towards technology infinite possibilities.

Integrity in business world is very crucial. A good business strategy will only last if every partner in the business holds on to integrity. On personal level, integrity also helps you to feel good about yourself and allow you to command high respect from your working colleagues and the society.

Confidentiality is basically respecting someone's privacy or requirement. Confidentiality leads to trust among each other. As trust is a basis for good business relationship, it should be practised by all leaders in managing corporations.

Empathy is one of the most important criteria among all mentioned above. Empathy means putting yourself in somebody's position and understands how your decision will affect them.

Imagine what would be the consequence by being careless, not being honest, being closed, no integrity, do not keep promises and exploiting confidentiality. To create a good working place environment, empathy is very vital. Immaterial which position you hold, you should be able to empathise everyone you are working with in order to create a harmonious working environment. This is one of the most important features of most of the organizations rated as the best companies to work for.

As a whole, the above acronym simply says that being ethical or unethical is your CHOICE. But the consequence of being unethical is heavy. Even though being ethical need to go through many challenges and the results could be slower, eventually, you will be in a better position to reap your investment.

By practising the above, organisations will be able to avoid being unethical. In addition, by having noble vision and mission, good administration (governance, transparency, control and measures); understanding inherent duty of a human being (working towards betterment of human being and making money in the process instead of the other way round); and practising integrity (taking control of yourself), you will be able to be ethical in all dealings.

\subsubsection{Legality}

Not every unethical business is illegal. Legality plays an important role in business sustainability which generally covers the four main areas as corporate governance, competition act, integrity commission and Country law.

Good governance is critical to avoid being unethical. Good governance starts from the top management (that includes board director of strategic direction and governance oversight) and cascades throughout the organization to all employees. Strategic direction directors are top management who has personal involvement and direct interest in the organization. They normally involve setting the organization direction based on vision and mission; and manage it towards achieving the organization's set goals.

Governance oversight directors could be people who do not have direct or personal interest in the organization. They are appointed to ensure the management of the organization practice good governance and ensure that the stakeholder's welfare is taken care. In another word, their key role is to prevent fraudulence that could victimize the stakeholder's investment. Corporate governance involves in creating good relationships among the board, senior management and shareholders and forming an organizational structure that adhere strictly to legal and regulatory environment. It also helps in attaining balances between economics and social goals that are extended to customers, suppliers, partners, creditors and the general community.

Good corporate governance uses various legal forms, structures, strategies and procedures to ensure that it complies with society's legal and regulatory rules. It is important to practice the generally accepted business norms, ethical precepts and social expectations of society that provides overall benefit to society and enhances the interests of the specific stakeholders in both the long and short-term. It is transparent and reports fully and truthfully to its owners, regulators, other stakeholders and general public to ensure accountability for its decisions, actions, conduct and performance.

Competition act is created to prevent market monopoly that will lead to competitive economy, which in turn will provide fair offering to all the stakeholders 
comprises of Government, Business and Customer. For government, it helps in establishing the correlation between competition and Gross Domestic Productivity (GDP), while create more opportunity for Free Trade Agreements (FTAs). For Business entities, it helps in spurring efficiency and innovation. It protects abuses by dominant firms, while allowing a level field where playing field where big and small, foreign and local businesses compete freely. Competitive act prevents developed country or large corporation to take advantages over developing countries or smaller organisation by dominating the market. It helps keep market open and competitive. For consumers, it creates a market with freedom of choices, which improves the bargaining power of customer where customer could choose the product they prefer at a competitive price.

Integrity commission is setup to promote the culture of zero corruption in public service, the private sector and civil society through advocacy, education, information and research. It works closely with all individuals and groups, with for profit and not for profit corporations and organizations and with governments and international bodies committed to the fight against corruption, subject only to the policies and priorities set by our governing bodies. Integrity commission undertakes to create openness, honesty and accountability the relationships among all the relevant parties such government, business and consumers.

Many organisations formulate entry and exit strategy without understanding the country law, particularly when dealing with exit strategy. Country laws can either support or deter business opportunities in respective countries. For example, pioneer status, tax incentives for particular product or technology would be the encouraging force to invest in a particular country. On the other hand, issues such as profit repatriation and human rights could be a discouraging factor in certain countries. Thus, these factors should be considered in determining the entry and exit strategies which determine their strategic agilities and should be included in their corporate strategies.

\subsubsection{Future}

Future needs generally comprises of the three main ones called economic needs, human needs and environmental needs. Among the three needs, the dominant needs in future will be human needs which will indirectly determine the business needs. The future human needs are space, air, energy, water and earth. As the above needs are reaching the scarcity level, future business need to ensure that these five elements are fulfilled. In order to avoid destruction of the above five elements, the business needs should be focused on fulfilling the needs of human being and not wants; quality of product and not quantity of product; every business or operation must optimize the efficiency and effectiveness to achieve zero defects and zero waste.

Based on maslow's hierarchy of needs, the basic human needs varies according to the market segment and the level of customers' maturity. There is an indication that shows that future key driver of business would be happiness of the customers which only can be attained via fulfilling the basic human needs. Hence, the corporate strategy should be able to fulfil these basic needs through the business needs.

In a nutshell, the foresight for future business should be based on key drivers on I-TOP model that includes technology infinite possibilities, outright environmental scanning, people-human capital development (Muthuveloo and Teoh, 2013). The facilitator between drivers and competitive advantage will be blue ocean strategy, disruptive innovation, business intelligence, global scenario planning and human capital management. The eventual final focus of a corporate strategy should be able to optimize ROI while ensuring sustainability via strategic agility.

In conclusion, business ethics and legality are crucial for sustainability. Future business will be driven by basic human needs such as space, air, energy, water and earth. These basic human needs will be translated in term of business needs via fulfilling needs not wants; focussing on quality instead of quantity; and working towards zero defects and zero waste. Future business will be towards providing happiness to the customers by fulfilling all the basic human needs. Corporate strategy should be formulated based on foresight and not forecast to be a WINNER.

\section{CONCLUSION}

Strategic Management Process has been evolving due to the continuous changes and demand by the stakeholders to curb unethical and illegal business transactions that will impact the organization as well as the community.

This study discussed an adapted strategic management model called SWIM which incorporates Scenario planning (S), Winning factors (W), Implementation (I) and Matching (M). Firstly, this 
study highlights that a strategic management process should start with strategic input process that provides a clear understanding of the organisation's purpose of existence, its current environmental dynamism and its core competitive or winning factor. This assists the organisation in formulating root cause corporate strategy that is vital for business sustainability. Then, it incorporates appropriate entry strategies, exit strategies and strategic agility into the corporate strategy to manage the changes in the environment that impact the business. Finally via matching, organisation would be able to ensure that the strategies and product/service offered are human and environmental friendly.

\section{REFERENCES}

Burgelman, R.A. and A.S. Grove, 2007. Let chaos reign, then rein in chaos-repeatedly: Managing strategic dynamics for corporate longevity. Strategic Manage. J., 28: 965-979. DOI: 10.2139/ssrn.959225

David, F.R., 2011. Strategic Management: Concepts and Cases. 13th Edn., Prentice Hall, Upper Saddle River, ISBN-10: 0136120989, pp: 290.
Haigh, N. and A. Griffiths, 2009. The natural environment as a primary stakeholder: The case of climate change. Bus. Strategy Environ., 18: $347-$ 359. DOI: $10.1002 /$ bse. 602

Jamali, D., 2008. A stakeholder approach to corporate social responsibility: A fresh perspective into theory and practice. J. Bus. Ethics, 82: 213-231. DOI: 10.1007/s10551-007-9572-4

Muthuveloo, R., 2013. Swimming in the Business World: Sustainability Through Corporate Strategy. 1st Edn., Pearson Malaysia, Kuala Lumpur, ISBN10: 9673492654, pp: 108.

Muthuveloo, R. and A.P. Teoh, 2013. Achieving business sustainability via I-TOP Model. Am. J. Econom. Bus. Administrat., 5: 15-21. DOI: 10.3844/ajebasp.2013.15.21

Pearce, J.A. and R.B. Robinson, 2013. Strategic Management: Planning for Domestic and Global Competition. 13th Edn., McGraw Hill, ISBN-10: 0071326391, pp: 434.

Teece, D.J., 2010. Business models, business strategy and innovation. Long Range Plann., 43: 172-194. DOI: $10.1016 /$ j.lrp.2009.07.003 